\title{
The Impact of Pravastatin Therapy on Long-Term Outcome in Patients With Metabolic Syndrome Undergoing Complete Coronary Revascularization
}

\author{
Takatoshi Kasai, MD; Katsumi Miyauchi, MD; Kan Kajimoto, MD*; Naozumi Kubota, MD; \\ Takeshi Kurata, MD; Atsushi Amano, MD*; Hiroyuki Daida, MD
}

\begin{abstract}
Background: Few studies dealing with the efficacy of statin therapy among patients with metabolic syndrome (MS) and coronary artery disease (CAD) have been conducted. In particular, there have been no studies of the efficacy of statins among Asian MS patients with treated CAD.

Methods and Results: Data from 1,138 consecutive patients who underwent complete revascularization (coronary intervention or bypass surgery) were collected. Of these, 529 patients who satisfied the criteria for MS using the American Heart Association/National Heart, Lung and Blood Institute statement (body mass index $\geq 25$ was used instead of waist circumference) were assessed. All-cause and cardiovascular mortality of patients given statins and those not given statins at least 2 weeks before the complete revascularization were compared. To adjust for the variables that would have been related to the decision to give statins, the propensity score was calculated, and multivariate Cox regression was carried out. Statins were given to 146 patients. During follow-up (9.1 \pm 2.5 years), 104 patients died. On multivariate analysis, statin use was significantly associated with reduced all-cause (hazard ratio (HR) 0.56, 0.31-0.99; $\mathrm{P}=0.049$ ) and cardiovascular (HR 0.53, 0.30-0.96; $\mathrm{P}=0.042$ ) mortality.

Conclusions: In patients with MS and CAD, statins given at least 2 weeks before the complete revascularization, was associated with a reduced risk of all-cause and cardiovascular mortality. (Circ J 2009; 73: 2104-2109)
\end{abstract}

Key Words: Coronary artery bypass grafting; Mortality; Percutaneous coronary intervention; Statin

$\mathbf{T}$ he prevalence of metabolic syndrome (MS), a cluster of dyslipidemia, hyperglycemia, hypertension, and obesity, is increasing, and MS is regarded as a key risk factor for cardiovascular morbidity and mortality. ${ }^{1-7} \mathrm{In}$ 2001, the third report of the National Cholesterol Education Program-Adult Treatment Panel recognized the importance of treating MS as a secondary target of cardiovascular risk reduction, beyond low-density lipoprotein-cholesterol lowering. ${ }^{8}$

\section{Editorial p 2013}

HMG-CoA reductase inhibitors (statins), which lower cholesterol, have been proven to reduce cardiovascular events in various patient populations. ${ }^{9-17}$ However, statins also improve other types of dyslipidemia, including decreased high-density lipoprotein (HDL)-cholesterol levels and increased triglycerides, and furthermore, statins have beneficial effects beyond cholesterol lowering, such as reducing oxidative stress and modulating inflammatory responses. ${ }^{18}$ These might affect other risk factors for cardiovascular diseases associated with MS. Some reports involving Western populations showed the beneficial effect of statin treatment in patients with MS and coronary artery disease $(\mathrm{CAD})$ by reducing recurrent cardiac events. ${ }^{19-21}$ However, there have been no studies that showed the long- term efficacy of statins in MS patients with CAD treated with complete coronary revascularization, especially in Asian populations. The aim of the present study was to assess whether the use of statins at least 2 weeks before the complete revascularization affects long-term mortality in Japanese patients with MS and CAD.

\section{Methods}

\section{Participants and Baseline Data Collection}

Data from consecutive patients who had undergone surgical and/or percutaneous coronary revascularization at Juntendo University Hospital between November 1987 and December 1992 were analyzed. Patients who met the following inclusion criteria were enrolled: (1) achieved complete revascularization, defined as no un-bypassed major vessels with a $\geq 50 \%$ stenosis; ${ }^{22,23}$ and (2) presence of MS according to the modified criteria of the American Heart Association/National Heart, Lung and Blood Institute (AHA/NHLBI) statement ${ }^{24}$ (obesity was defined as body mass index (BMI) $\geq 25 \mathrm{~kg} / \mathrm{m}^{2}$ according to the Japanese criteria for obesity, 25 instead of using waist circumference as in the AHA/NHLBI statement) at the time when complete revascularization was achieved. Patients who had other known life-threatening diseases at baseline and patients who had associated complex cardiac procedures, such as

Received February 19, 2009; revised manuscript received June 18, 2009; accepted June 23, 2009; released online August 28, 2009

Department of Cardiology, *Department of Cardiovascular Surgery, Juntendo University, School of Medicine, Tokyo, Japan

Mailing address: Katsumi Miyauchi, MD, Department of Cardiology, Juntendo University, School of Medicine, 2-1-1 Hongo, Bunkyo-ku,

Tokyo 113-8421, Japan. E-mail: ktmmy@med.juntendo.ac.jp

All rights are reserved to the Japanese Circulation Society. For permissions, please e-mail: cj@j-circ.or.jp 
Table 1. Baseline Characteristics

\begin{tabular}{lccc}
\hline & No-statin $(\mathrm{n}=383)$ & Statin $(\mathrm{n}=146)$ & P value \\
\hline Age, years & $59.5 \pm 8.6$ & $59.8 \pm 9.5$ & 0.73 \\
Male, $\mathrm{n}(\%)$ & $318(83.0)$ & $120(82.2)$ & 0.80 \\
BMI, kg/m & $24.7 \pm 2.5$ & $24.8 \pm 2.6$ & 0.67 \\
Diabetes mellitus, $\mathrm{n}(\%)$ & $66(37.1)$ & $31(40.8)$ & 0.29 \\
Hypertension, $\mathrm{n}(\%)$ & $287(74.9)$ & $108(74.0)$ & 0.82 \\
Total cholesterol, mg/dl & $215.4 \pm 47.5$ & $212.7 \pm 50.5$ & 0.57 \\
HDL-cholesterol, mg/dl & $36.4 \pm 10.3$ & $38.1 \pm 9.8$ & 0.73 \\
Triglyceride, mg/dl & $202.1 \pm 123.1$ & $194.6 \pm 82.8$ & 0.50 \\
Current smoker, $\mathrm{n}(\%)$ & $278(72.6)$ & $107(73.3)$ & 0.91 \\
Family history of CAD, $\mathrm{n}(\%)$ & $123(32.1)$ & $48(32.9)$ & 0.92 \\
Previous MI, $\mathrm{n}(\%)$ & $190(49.6)$ & $60(41.1)$ & 0.098 \\
Previous stroke, $\mathrm{n}(\%)$ & $27(7.1)$ & $4(2.7)$ & 0.064 \\
Atrial fibrillation, $\mathrm{n}(\%)$ & $53(13.8)$ & $14(9.6)$ & 0.24 \\
On dialysis, $\mathrm{n}(\%)$ & $11(2.9)$ & $2(1.4)$ & 0.53 \\
LVEF, $\%$ & $63.9 \pm 13.6$ & $96.3 \pm 11.5$ & 0.062 \\
LMT lesion, $\mathrm{n}(\%)$ & $32(8.4)$ & $51(6.2)$ & 0.40 \\
Arterial bypass graft to LAD, $\mathrm{n}(\%)$ & $185(48.3)$ & $98(67.1)$ & 0.006 \\
Multivessel disease, $\mathrm{n}(\%)$ & $297(77.5)$ & $70(48.0)$ & 0.014 \\
Isolated PCI, $\mathrm{n}(\%)$ & $107(27.9)$ & $86(58.9)$ & $<0.001$ \\
Procedure date $\geq$ median, $\mathrm{n}(\%)$ & $178(46.5)$ & 0.014 \\
\hline
\end{tabular}

BMI, body mass index; HDL, high-density lipoprotein; CAD, coronary artery disease; MI, myocardial infarction; LVEF, left ventricular ejection fraction; LMT, left main trunk; LAD, left anterior descending; PCI, percutaneous coronary intervention.

valve replacement or aneurysm repair at the time of surgical revascularization, were excluded.

Demographic data, including age, gender, and BMI, coronary risk factors (blood pressure, lipid profile, fasting plasma glucose, smoking status, family history of CAD), medication use, revascularization procedure-related factors, comorbidities (previous myocardial infarction (MI) or stroke, on dialysis, and atrial fibrillation) were prospectively collected in the database at our institution.

For all analyses, the patients were divided into 2 groups according to statin use at least 2 weeks before the complete revascularization. Each patient was further categorized based on the presence of coronary risk factors using the following criteria during the study period: diabetes mellitus was defined as fasting blood glucose $\geq 140 \mathrm{mg} / \mathrm{dl}$ or treatment with oral hypoglycemic drugs or insulin injection; hypertension was defined as systolic blood pressure $\geq 140 \mathrm{mmHg}$ or diastolic blood pressure $\geq 90 \mathrm{mmHg}$ or treatment with antihypertensive medications. A current smoker was defined as one who smoked at the time of complete revascularization or who had stopped smoking within 1 year before complete revascularization. Atrial fibrillation was defined as persistent or permanent atrial fibrillation at the time of the procedure. Patients with isolated percutaneous coronary intervention (PCI) were those in whom complete revascularization was achieved by PCI without any bypass grafting.

This study was performed according to the ethics policies of the institution, and it was approved by the internal review board.

\section{Outcomes}

Survival data were collected by serial contact (every 5 years) with the patients or their families until September 30, 2000 and from the medical records of patients who had died and of those who continued to be followed up at our hospital. Information about the continuation of statins and the circumstances and date of death was obtained from the families of patients who died at home, and the cause of death was supplied by other hospitals or clinics where patients had been admitted. Mortality data were categorized according to the cause of death, such as death from all causes or cardiovascular death due to CAD, stroke, cardiogenic shock, and sudden death.

\section{Statistical Analysis}

Continuous variables are expressed as means \pm SD and compared using Student's t-test. Categorical data are displayed as frequencies and percentages and compared using the chi-squared test or Fisher's exact test. Kaplan-Meier estimates with the log-rank test and Cox proportional hazards models were used for survival analyses. To adjust the variables that would have been related to the decision regarding statin therapy at the time of revascularization, propensity analysis was used. ${ }^{26-29}$

Propensity analysis aims to identify patients with similar probabilities of receiving statins on the basis of the observed clinical characteristics. Variables included in the stepwise multivariate logistic regression analysis were: age, gender, BMI, total and HDL-cholesterol levels, triglyceride level, hypertension, diabetes mellitus, current smoker, family history of CAD, previous MI, previous stroke, on dialysis, atrial fibrillation, use of nitrates, angiotensin-converting enzyme inhibitors, $\beta$-blockers, calcium channel blockers, aspirin, other lipid-lowering drugs, and revascularization procedure date (before or after the median procedure date, September 10, 1990).

Based on the results of this logistic regression analysis, the propensity score was calculated for each patient. The propensity score was related to the probability of receiving statin therapy; a higher propensity score indicated a higher probability of being allocated to the statin group in the present study.

In addition to the crude model, 4 multivariate Cox proportional hazards models (Model 1: adjusted for age, gender, BMI, current smoker, hypertension and diabetes mellitus; Model 2: adjusted for variables included in Model 1 and the propensity score; Model 3: adjusted for age, gender, BMI, current smoker, hypertension, diabetes mellitus, use of nitrates, use of other lipid-lowering drugs, use of aspirin, 
Table 2. Use of Medications

\begin{tabular}{lccc}
\hline & No-statin $(\mathrm{n}=383)$ & Statin $(\mathrm{n}=146)$ & P value \\
\hline Nitrates, $\mathrm{n}(\%)$ & $353(92.2)$ & $126(86.3)$ & 0.046 \\
ACE-Is, $\mathrm{n}(\%)$ & $29(7.6)$ & $14(9.6)$ & 0.48 \\
CCBs, $\mathrm{n}(\%)$ & $175(45.7)$ & $61(41.8)$ & 0.44 \\
$\beta$-blockers, $\mathrm{n}(\%)$ & $142(37.1)$ & $51(34.9)$ & 0.69 \\
Other lipid-lowering drugs, $\mathrm{n}(\%)$ & $68(17.8)$ & $8(5.5)$ & $<0.0001$ \\
Aspirin, $\mathrm{n}(\%)$ & $214(55.9)$ & $99(67.8)$ & 0.013 \\
\hline
\end{tabular}

$\mathrm{ACE}$, angiotensin-converting enzyme; $\mathrm{CCB}$, calcium channel blockers.

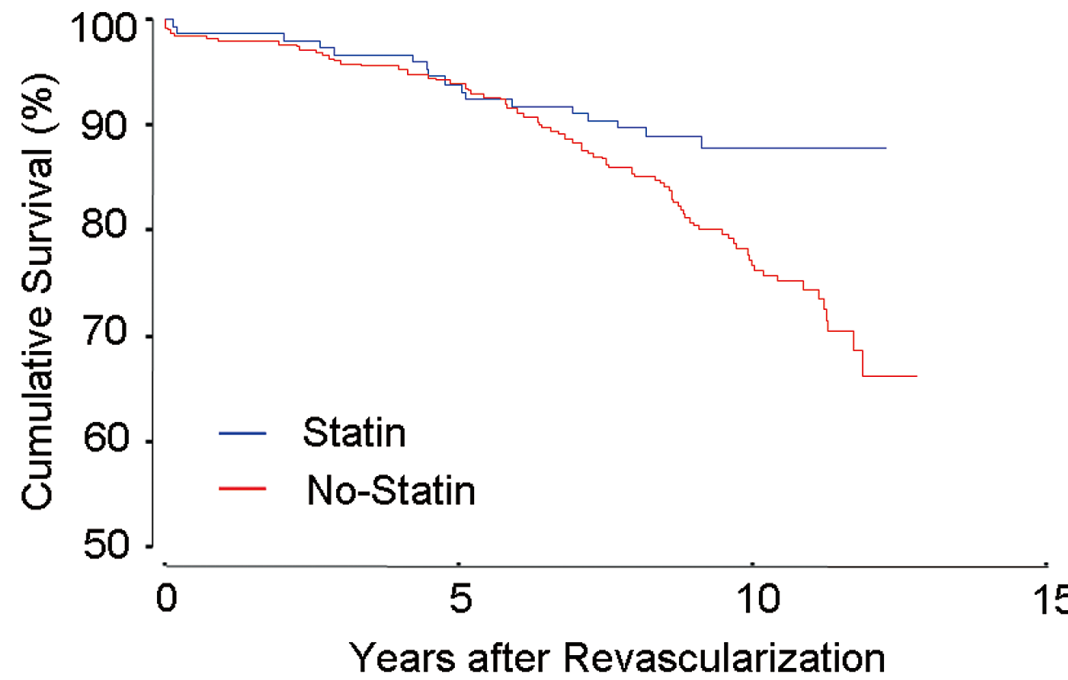

$\begin{array}{lrrr}\text { Numbers at } & \text { Risk } & & \\ \text { No-statin } & 383 & 355 & 153 \\ \text { Statin } & 146 & 135 & 51\end{array}$

Figure 1. Survival curves (all-cause death) of patients with and without statin therapy. There is a statistically significant difference between patients taking statin and patients not taking statin at the time when complete revascularization was achieved $(\mathrm{P}=0.015)$.

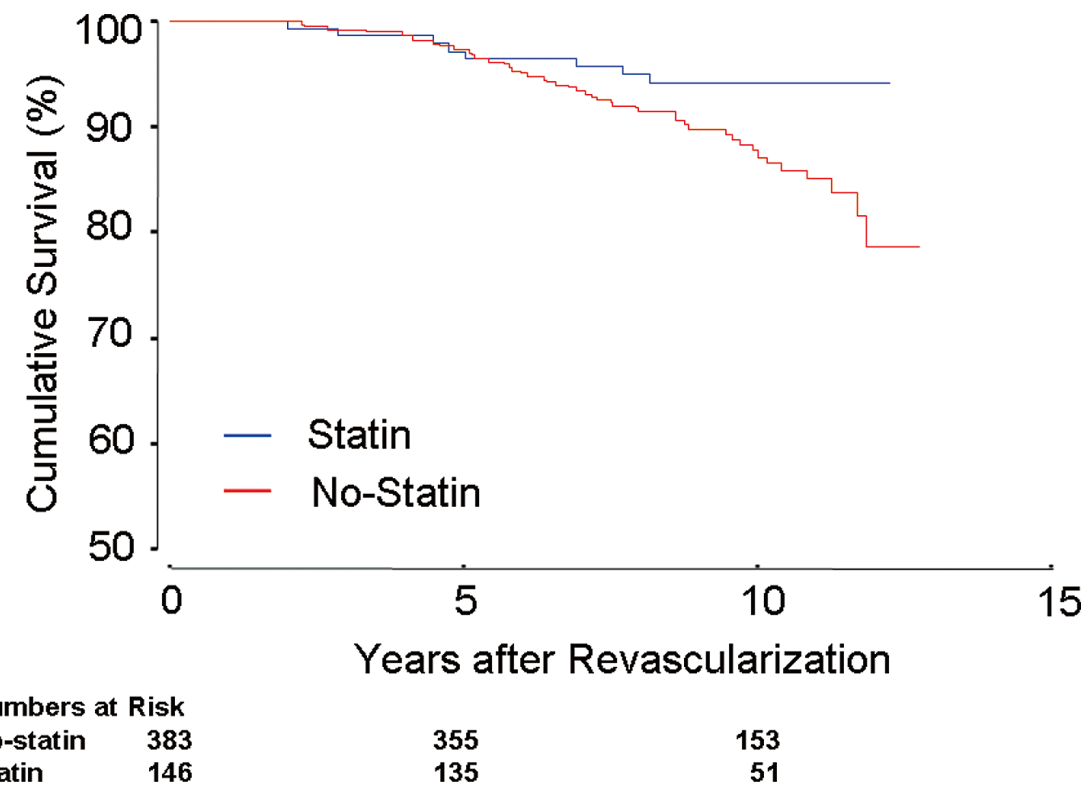

Figure 2. Survival curves (cardiovascular death) of patients with and without statin therapy. A statistically significant difference is observed between patients taking statin and patients not taking statin at the time when complete revascularization was achieved $(\mathrm{P}=0.025)$.

previous MI, previous stroke, left ventricular ejection fraction, multivessel disease, arterial bypass graft to the LAD, whether complete revascularization was achieved by isolated PCI, and the revascularization procedure date; Model 4: variables included in Model 3 and the propensity score) were used to determine the benefit of statin therapy as mea- sured by all-cause and cardiovascular death.

P-values $<0.05$ were considered significant. All data were analyzed using Dr. SPSS II for Windows (SPSS Inc, Chicago, IL, USA). 
Table 3. HR of Statin Use for All-Cause and Cardiovascular Mortality

\begin{tabular}{lccccccc}
\hline & \multicolumn{3}{c}{ All-cause death } & & \multicolumn{3}{c}{ Cardiovascular death } \\
\cline { 2 - 3 } \cline { 5 - 7 } & HR & $95 \%$ CI & P value & & HR & 95\%CI & P value \\
\hline Crude & 0.53 & $0.32-0.89$ & 0.017 & & 0.48 & $0.23-0.85$ & 0.035 \\
Model 1 & 0.47 & $0.28-0.80$ & 0.005 & & 0.44 & $0.21-0.93$ & 0.033 \\
Model 2 & 0.53 & $0.31-0.90$ & 0.019 & & 0.49 & $0.23-0.81$ & 0.038 \\
Model 3 & 0.57 & $0.30-0.97$ & 0.045 & & 0.54 & $0.29-0.96$ & 0.042 \\
Model 4 & 0.56 & $0.31-0.99$ & 0.049 & & 0.53 & $0.30-0.96$ & 0.042 \\
\hline
\end{tabular}

In Model 1, the HRs and 95\%CIs were adjusted for age, gender, BMI, current smoker, hypertension, and diabetes mellitus.

In Model 2, the HRs and 95\%CIs were adjusted for variables included in Model 1 and the propensity score.

In Model 3, the HRs and 95\%CIs were adjusted for age, gender, BMI, current smoker, hypertension, diabetes mellitus, use of nitrates, use of other lipid-lowering drugs, use of aspirin, previous MI, previous stroke, LVEF, multivessel disease, arterial bypass graft to LAD, whether complete revascularization was achieved by isolated PCI, and revascularization procedure date.

In Model 4, the HRs and 95\%CIs were adjusted for variables included in Model 3 and the propensity score.

$\mathrm{HR}$, hazard ratio; CI, confidence interval. Other abbreviations see in Table 1.

\section{Results}

\section{Baseline Characteristics}

Overall, complete revascularization was achieved in 1,138 patients during the study period. Of these, 529 (46.5\%) patients had MS. Baseline characteristics and clinical events during follow-up (mean, 9.1 \pm 2.5 years) were collected for all of these patients. Of these patients, $146(27.6 \%)$ received statins at the time when complete revascularization was achieved. Pravastatin 10 or $20 \mathrm{mg} /$ day was given at least 2 weeks before the revascularization procedure in all of these cases. During the total follow-up period, 12 patients $(8.2 \%)$ in the statin group stopped statin therapy, and 62 patients $(16.2 \%)$ in the non-statin group started statin therapy. The baseline characteristics of the patients with and without statins are shown in Table 1. More cases with an arterial bypass graft to the LAD and multivessel disease were included in the no-statin group. However, more cases in the statin group underwent complete revascularization by isolated PCI and were revascularized more recently (after 10 September, 1990). More patients were given aspirin in the statin group; however, fewer patients were given nitrates and other lipid-lowering drugs (Table 2). There were no significant differences between the 2 groups in any other variables. In addition, there were 111 patients whose initial presentation is acute coronary syndrome including unstable angina and acute MI: 32 (21.9\%) patients in the statin group and $79(20.6 \%)$ in the no-statin group ( $\mathrm{P}=0.836)$. All patients underwent PCI with balloon angioplasty; no patients received stent implantation, because stents were not yet available at the time of complete revascularization. All CABG procedures were performed under conventional cardiopulmonary bypass, and $44.6 \%$ involved arterial grafts.

\section{Survival Analyses}

In the propensity score analysis, independent variables associated with pravastatin use at the time when complete revascularization was achieved included: HDL-cholesterol level, previous MI, previous stroke, currently taking nitrates, aspirin, and other lipid-lowering drugs, and revascularization procedure date. The adequacy of the propensity score was confirmed because the area under the receiver operating characteristics curve was 0.74 . Patients on statin therapy had a mean propensity score of $0.502 \pm 0.114$, whereas patients not on statin therapy had a mean propensity score of $0.229 \pm 0.109$. The ability of the propensity score to adjust for baseline covariates of statin therapy was evaluated by testing for differences in these covariates within quintiles of the propensity score; the values for important variables associated with statin therapy were found to be not significantly different between the statin group and the no-statin group.

Overall, 104 patients died during follow-up (87 in the nostatin group, 17 in the statin group); of these, 54 were cardiovascular deaths (46 in the no-statin group, 8 in the statin group). Based on the survival curve, statin use at the time when complete revascularization was achieved was significantly associated with a reduction in long-term mortality from all causes and cardiovascular death (Figures 1,2). Using several Cox proportional hazards model, statin use at least 2 weeks before the complete revascularization was an independent and significant predictor of long-term survival in all models, both with respect to death from all causes and cardiovascular death (Table 3).

\section{Discussion}

Our registry data showed that, in patients with MS and $\mathrm{CAD}$, pravastatin therapy at the time when complete revascularization was achieved was associated with a reduction in long-term all-cause and cardiovascular mortality. Previous reports showed that MS patients with $\mathrm{CAD}$ were at significantly higher long-term cardiovascular risk than those without MS. In the present study, it was shown that this increased risk in MS patients might be significantly reduced by pravastatin therapy.

The present study might provide at least 2 important messages. The first one is that MS patients who undergo coronary revascularization are good candidates for statin therapy. In the present study, although the changes in the lipid profile between before and after initiation of pravastatin therapy were not shown, the cholesterol level at the time when complete revascularization was achieved was relatively well-controlled in both the statin and the nostatin groups and was not different between the 2 groups. Even under such conditions, patients with pravastatin had a significantly lower long-term mortality than those without pravastatin at the time when complete revascularization was achieved. This better prognosis in patients with pravastatin might be associated with the additional effects of statins, such as increasing HDL-cholesterol, decreasing triglycerides, reduction of oxidative stress and suppressing inflammation, which are associated with the MS. ${ }^{18}$ In addition, considering a recent report that showed that administration of pravastatin $10 \mathrm{mg}$ for 6 months raises serum levels of adiponectin, which is a key molecule of MetS in 
Japanese population, such a pleiotropic effect might also affect the better prognosis. ${ }^{30}$

The second message is that pravastatin therapy was associated with an improved long-term outcome even in patients with CAD treated with complete revascularization. Although several studies showed the efficacy of statins in MS patients with evident CAD, ${ }^{19-21}$ it is not clear whether the patients who enrolled in those studies had undergone coronary revascularization. To the best of our knowledge, there have been no reports involving patients who had significant CAD but who had been treated with coronary revascularization. Furthermore, it is important to emphasize the benefit of assessing data only in patients who had achieved complete revascularization, because the initial $\mathrm{CAD}$ events were reset by complete coronary revascularization, even in patients with severe coronary atherosclerosis. This might minimize the bias of the treatment procedure for the initial CAD events. Therefore, the efficacy of statin therapy for cardiovascular disease among a secondary prevention cohort of patients with MS and CAD could be assessed.

Additionally, there are no data regarding the efficacy of statin therapy for secondary prevention of cardiovascular disease in an Asian MS population. Therefore, this is the first Asian report to show the efficacy of statins among MS patients with CAD, even though statin therapy was not randomly allocated in the present study.

Interestingly, survival curves in the present study showed that the difference between statin and no-statin group was more apparent after 5 years. This observation is quite different from other reports that showed the efficacy of statins in other patient population. ${ }^{9-17,28}$ This might be associated with that the initial CAD events were reset by complete coronary revascularization. However, there is a possibility that such observation is specifically observed in patients with MS. It was reported that patients with MS have a high risk for diabetes mellitus ${ }^{1}$ and the statins might reduce the incidence new onset diabetes mellitus or delay the progression of diabetes mellitus. ${ }^{31,32}$ Therefore, it was also suggested that in the present study, pravastatin prevented incidence of or progression of diabetes mellitus during the initial 5 years and then the patients with new onset diabetes mellitus or advanced diabetes mellitus affect the reduced mortality of the no-statin group. However, because the data about new onset diabetes is not available in the present study, we can not clarify the specific reason.

\section{Study Limitations}

First, this was a single center, observational study of daily clinical practice. Although propensity analyses are powerful, ${ }^{33}$ they are inherently limited by the number and accuracy of the variables evaluated.

Second, in the present study, the total duration of statin use after complete revascularization was not examined, and there was some crossover between the 2 groups. However, this crossover bias would probably have led to underestimation of the association between statin administration and survival. Therefore, this further emphasizes that statin therapy at least 2 weeks before the complete revascularization was associated with better long-term all-cause and cardiovascular mortality. Although this might have affected the results of the present study, the effect was probably very small.

Third, since all patients underwent revascularization 1520 years ago, several essential drugs such as aspirin and angiotensin-converting enzyme inhibitor were used less frequently in this cohort as compared with in those patients in the present study. These might amplify the effects of pravastatin more than its effect observed in current medical practice. Therefore, the findings of the study should be interpreted with caution.

\section{Conclusion}

In the present study involving consecutive revascularization patients with MS, the use of pravastatin significantly reduced long-term all-cause and cardiovascular mortality after complete revascularization.

\section{References}

1. Wilson PW, D'Agostino RB, Parise H, Sullivan L, Meigs JB. Metabolic syndrome as a precursor of cardiovascular disease and type 2 diabetes mellitus. Circulation 2005; 112: 3066-3072.

2. McNeill AM, Rosamond WD, Girman CJ, Golden SH, Schmidt MI, East HE, et al. The metabolic syndrome and 11-year risk of incident cardiovascular disease in the Atherosclerosis Risk in Communities Study. Diabetes Care 2005; 28: 385-390.

3. Takeuchi H, Saitoh S, Takagi S, Ohnishi H, Ohhata J, Isobe T, et al. Metabolic syndrome and cardiac disease in Japanese Men: Applicability of the concept of metabolic syndrome defined by the National Cholesterol Education Program-Adult Treatment Panel III to Japanese Men-The Tanno and Sobetsu Study. Hypertens Res 2005; 28: $203-$ 208.

4. Eberly LE, Prineas R, Cohen JD, Vazquez G, Zhi X, Neaton JD, et al; Multiple Risk Factor Intervention Trial Research Group. Metabolic syndrome: Risk factor distribution and 18-year mortality in the multiple risk factor intervention trial. Diabetes Care 2006; 29: $123-130$.

5. Sundstrom J, Riserus U, Byberg L, Zethelius B, Lithell H, Lind L. Clinical value of the metabolic syndrome for long term prediction of total and cardiovascular mortality: Prospective, population based cohort study. BMJ 2006; 332: 878-882.

6. Kasai T, Miyauchi K, Kurata T, Ohta H, Okazaki S, Miyazaki T, et al. Prognostic value of the metabolic syndrome for long-term outcomes in patients undergoing percutaneous coronary intervention. Circ J 2006; 70: 1531-1537.

7. Kajimoto K, Kasai T, Miyauchi K, Hirose H, Yanagisawa N, Yamamoto T, et al. Metabolic syndrome predicts 10-year mortality in non-diabetic patients following coronary artery bypass surgery. Circ J 2008; 72: 1481-1486.

8. Expert Panel on Detection, Evaluation, and Treatment of High Blood Cholesterol in Adults. Executive Summary of the Third Report of the National Cholesterol Education Program (NCEP) Expert Panel on Detection, Evaluation, and Treatment of High Blood Cholesterol in Adults (Adult Treatment Panel III). JAMA 2001; 285: 2486-2497.

9. Scandinavian Simvastatin Survival Study Group. Randomised trial of cholesterol lowering in 4444 patients with coronary heart disease: The Scandinavian Simvastatin Survival Study (4S). Lancet 1994; 344: $1383-1389$.

10. Shepherd J, Cobbe SM, Ford I, Isles CG, Lorimer AR, MacFarlane $\mathrm{PW}$, et al. Prevention of coronary heart disease with pravastatin in men with hypercholesterolemia: West of Scotland Coronary Prevention Study Group. N Engl J Med 1995; 333: 1301-1307.

11. Sacks FM, Pfeffer MA, Moye LA, Rouleau JL, Rutherford JD, Cole $\mathrm{TG}$, et al. The effect of pravastatin on coronary events after myocardial infarction in patients with average cholesterol levels: Cholesterol and Recurrent Event Trial Investigators. N Engl J Med 1996; 335: $1001-1009$.

12. The Long-Term Intervention with Pravastatin in Ischemic Disease (LIPID) Study Group. Prevention of cardiovascular events and death with pravastatin in patients with coronary heart disease and a broad range of initial cholesterol levels. N Engl J Med 1998; 339: 13491357.

13. Downs JR, Clearfield M, Weis S, Whitney E, Shapiro DR, Beere PA, et al. Primary prevention of acute coronary events with lovastatin in men and women with average cholesterol levels: Results of AFCAPS/ TexCAPS: Air Force/Texas Coronary Atherosclerosis Prevention Study. JAMA 1998; 279: 1615-1622.

14. Schwartz GG, Olsson AG, Ezekowitz MD, Ganz P, Oliver MF, Waters D, et al. Effects of atorvastatin on early recurrent ischemic events in acute coronary syndromes: The MIRACL study: A ran- 
domized controlled trial. JAMA 2001; 285: 1711-1718.

15. Sever PS, Dahlöf B, Poulter NR, Wedel H, Beevers G, Caulfield M, et al. Prevention of coronary and stroke events with atorvastatin in hypertensive patients who have average or lower-than-average cholesterol concentrations, in the Anglo-Scandinavian Cardiac Outcomes Trial-Lipid Lowering Arm (ASCOT-LLA): A multicentre randomized controlled trial. Lancet 2003; 361: 1149-1158.

16. Cannon CP, Braunwald E, McCabe CH, Rader DJ, Rouleau JL, Belder R, et al; Pravastatin or Atorvastatin Evaluation and Infection Therapy-Thrombolysis in Myocardial Infarction 22 Investigators. Intensive versus moderate lipid lowering with statins after acute coronary syndromes. $N$ Engl J Med 2004; 350: 1495-1504.

17. LaRosa JC, Grundy SM, Waters DD, Shear C, Barter P, Fruchart JC, et al. Intensive lipid lowering with atorvastatin in patients with stable coronary disease. N Engl J Med 2005; 352: 1425-1435.

18. Liao JK. Beyond lipid lowering: The role of statins in vascular protection. Int J Cardiol 2002; 86: 5-18.

19. Pyörälä K, Ballantyne CM, Gumbiner B, Lee MW, Shah A, Davies MJ, et al, Scandinavian Simvastatin Survival Study (4S). Reduction of cardiovascular events by simvastatin in nondiabetic coronary heartdisease patients with and without the metabolic syndrome: Subgroup analyses of the Scandinavian Simvastatin Survival Study (4S). Diabetes Care 2004; 27: 1735-1740.

20. Schwartz GG, Olsson AG, Szarek M, Sasiela WJ. Relation of characteristics of metabolic syndrome to short-term prognosis and effects of intensive statin therapy after acute coronary syndrome: An analysis of the Myocardial Ischemia Reduction with Aggressive Cholesterol Lowering (MIRACL) trial. Diabetes Care 2005; 28: 2508-2513.

21. Deedwania P, Barter P, Carmena R, Fruchart JC, Grundy SM, Haffner $\mathrm{S}$, et al; for the Treating to New Targets Investigators. Reduction of low-density lipoprotein cholesterol in patients with coronary heart disease and metabolic syndrome: Analysis of the Treating to New Targets study. Lancet 2006; 368: 919-928.

22. Jones EL, Weintraub WS. The importance of completeness of revascularization during long-term follow-up after coronary artery operations. J Thorac Cardiovasc Surg 1996; 112: 227-237.

23. McLellan CS, Ghali WA, Labinaz M, Davis RB, Galbraith PD, Southern DA, et al, Alberta Provincial Project for Outcomes Assessment in Coronary Heart Disease (APPROACH) Investigators. Asso- ciation between completeness of percutaneous coronary revascularization and postprocedure outcomes. Am Heart J 2005; 150: 800-806.

24. Grundy SM, Cleeman JI, Daniels SR, Donato KA, Eckel RH, Franklin BA, et al. Diagnosis and management of the metabolic syndrome: An American Heart Association/National Heart, Lung and Blood Institute scientific statement. Circulation 2005; 112: $2735-$ 2752.

25. Examination Committee of Criteria for 'Obesity Disease' in Japan; Japan Society for the Study of Obesity: New criteria for 'obesity disease' in Japan. Circ J 2002; 66: 987-992.

26. Rubin DB. Estimating causal effects from large data sets using propensity scores. Ann Intern Med 1997; 127: 757-763.

27. Brener SJ, Lytle BW, Casserly IP, Schneider JP, Topol EJ, Lauer MS. Propensity analysis of long-term survival after surgical or percutaneous revascularization in patients with Multivessel coronary artery disease and high-risk features. Circulation 2004; 109: 22902295 .

28. Kasai T, Miyauchi K, Kurata T, Satoh H, Ohta H, Tanimoto K, et al. Long-term (11-year) statin therapy following percutaneous coronary intervention improves clinical outcome and is not associated with increased malignancy. Int J Cardiol 2007; 114: 210-217.

29. Ikeda E, Kasai T, Kajimoto K, Miyauchi K, Kubota N, Kurata T, et al. Dipyridamole therapy improves long-term survival after complete revascularization in patients with impaired cardiac function: A propensity analysis. Circ J 2008; 72: 1588-1593.

30. Sakamoto K, Sakamoto T, Ogawa H; Kumamoto Joint Research on Hypercholesterolemia Investigators. The effect of 6 months of treatment with pravastatin on serum adiponection concentrations in Japanese patients with coronary artery disease and hypercholesterolemia: A pilot study. Clin Ther 2006; 28: 1012-1021.

31. Freeman DJ, Norrie J, Sattar N, Neely RD, Cobbe SM, Ford I, et al. Pravastatin and the development of diabetes mellitus: Evidence for a protective treatment effect in the West of Scotland Coronary Prevention Study. Circulation 2001; 103: 357-362.

32. Yee A, Majumdar SR, Simpson SH, McAlister FA, Tsuyuki RT, Johnson JA. Statin use in Type 2 diabetes mellitus is associated with a delay in starting insulin. Diabet Med 2004; 21: 962-967.

33. Radford MJ, Foody JM. How do observational studies expand the evidence base for therapy? JAMA 2001; 286: 1228-1230. 